\author{
Anna ZASTAWNA-RUMIN ${ }^{1}$ \\ Katarzyna NOWAK ${ }^{2}$
}

\title{
POMIAR WŁAŚCIWOŚCI CIEPLNYCH MATERIAŁÓW BUDOWLANYCH PRZY ZASTOSOWANIU RÓŻNEJ APARATURY POMIAROWEJ - ANALIZA WYNIKÓW
}

\begin{abstract}
Celem artykułu jest weryfikacja parametrów termicznych materiałów budowlanych otrzymanych przy użyciu dwóch różnych metod pomiarowych. Metody pomiarowe parametrów termicznych można podzielić na dwie zasadnicze grupy: metody stacjonarne (realizowane przy ustalonym strumieniu cieplnym) oraz metody niestacjonarne (realizowane przy nieustalonym strumieniu cieplnym). W artykule analizowano możliwość prowadzenia stosunkowo szybkich badań przy użyciu urządzenia przenośnego, którego działanie oparte jest na metodzie dynamicznej. Wyniki porównywano do wartości otrzymanych z pomiarów wykonanych metodą stacjonarną $\mathrm{w}$ bardzo dokładnym i rekomendowanym aparacie płytowy. Badaniom poddano próbki popularnie stosowanych materiałów dociepleniowych tj.: sztywnej pianki poliuretanowej, styropianu i wełny mineralnej (mat miękkich oraz twardych płyt) o grubościach $4-6 \mathrm{~cm}$ i $10 \mathrm{~cm}$. Analizowano także możliwość stosowania różnych rodzajów sond pomiarowych, które współpracują z urządzeniem przenośnym. Dużą zaletą urządzenia przenośnego jest możliwość jego użycia podczas badań polowych. Niestety przeprowadzona analiza wykazała, że w przypadku materiałów termoizolacyjnych dokładność tej metody można uznać za wysoką jedynie w przypadku warstw o grubości $10 \mathrm{~cm}$. W przypadku cieńszych warstw materiału $(0 \mathrm{k} .5 \mathrm{~cm})$ uzyskane wyniki mogą być obarczone znacznym błędem. Na podstawie przeprowadzonych badań dla wąskiego zakresu materiałów termoizolacyjnych zaobserwowano, iż wyniki uzyskane z pomiarów wykonanych przy użyciu przyrządu Isomet są w większości przypadków wynikami zawyżonymi (w porównaniu z wynikami otrzymanymi z pomiarów w aparacie płytowym jak i wartościami zawartymi w specyfikacji producenta).
\end{abstract}

Słowa kluczowe: współczynnik przewodzenia ciepła, przewodność, badania parametrów termicznych

\footnotetext{
${ }^{1}$ Autor do korespondencji: Anna Zastawna-Rumin, Politechnika Krakowska, ul. Warszawska 24, 31-155 Kraków, zastawna.anna@ gmail.com

${ }^{2}$ Katarzyna Nowak, Politechnika Krakowska, ul. Warszawska 24, 31-155 Kraków, kaskanowa@poczta.onet.pl
} 


\section{Metody pomiarowe}

\subsection{Wstęp}

Wymóg budowania obiektów jak najbardziej energooszczędnych skutkuje zwiększeniem roli materiałów termoizolacyjnych. Podstawowym parametrem termicznym, który bierze się pod uwagę przy wyborze takiego materiału jest współczynnik przewodzenia ciepła. Wartość tego współczynnika istotnie wpływa na efektywność użytej warstwy termoizolacyjnej oraz jej minimalną grubość, która pozwoli na spełnienie wymagań cieplnych stawianych przegrodom budowlanym [6].

Metody pomiarowe parametrów termicznych materiałów budowlanych można podzielić na dwie zasadnicze grupy: metody stacjonarne (realizowane przy ustalonym strumieniu cieplnym) oraz metody niestacjonarne (realizowane przy nieustalonym strumieniu cieplnym). Metody stacjonarne są metodami dostarczającymi dokładniejszych wyników. Wadą tych metod jest uzależnienie długości czasu niezbędnego do przeprowadzenia pomiarów od uzyskania stanu ustalonego. Metody niestacjonarne nie mają takiej dokładności jak metody stacjonarne, pozwalają jednak na szybki pomiar. [3,4]

\subsection{Metoda stacjonarna pomiaru parametrów cieplnych i opis użytej aparatury}

W metodach ustalonego strumienia ciepła strumień przechodzący przez próbkę materiału powinien być stały co do wartości, a temperatura powierzchni ustalona. Współczynnik przewodzenia ciepła badanego materiału określa się mierząc gęstość strumienia cieplnego i różnicę temperatur po obu stronach próbki. Wartości współczynnika przewodzenia ciepła i oporu cieplnego są w takim przypadku obliczane z równania Fouriera (1), przy założeniu jednowymiarowego przepływu ciepła. [4]

$$
Q=-\lambda \cdot \operatorname{grad} T\left[\mathrm{~W} / \mathrm{m}^{2}\right]
$$

gdzie: $\lambda$-współczynnik przewodzenia ciepła $[\mathrm{W} / \mathrm{m} \cdot \mathrm{K}]$

$\mathrm{T}$ - temperatura $[\mathrm{K}]$

Pomiar metodą stacjonarną można przeprowadzić przy użyciu aparatu płytowego. Badanie możliwe jest tylko w laboratorium i wymaga dostarczenia próbki badanego materiału o wymiarach $30 \mathrm{~cm}$ x $30 \mathrm{~cm}$.

Inną metodą stacjonarną pozwalającą na wyznaczenie parametrów izolacyjności termicznej materiałów lub oporu cieplnego przegród wielowarstwowych jest metoda ścianki pomocniczej. Głównym założeniem metody jest równość wartości strumieni przepływających przez ciepłomierz przymocowany do badanej przegrody i przez samą badaną przegrodę. Pomiar tą metodą powinien 
być przeprowadzany w tzw. komorach klimatycznych, w których warunki brzegowe są ustalone. Pomimo swojego założenia o ustalonym strumieniu ciepła metoda umożliwia również wyznaczenie parametrów termicznych przegrody w warunkach niestacjonarnych. Jest to możliwe pod warunkiem wyznaczenia

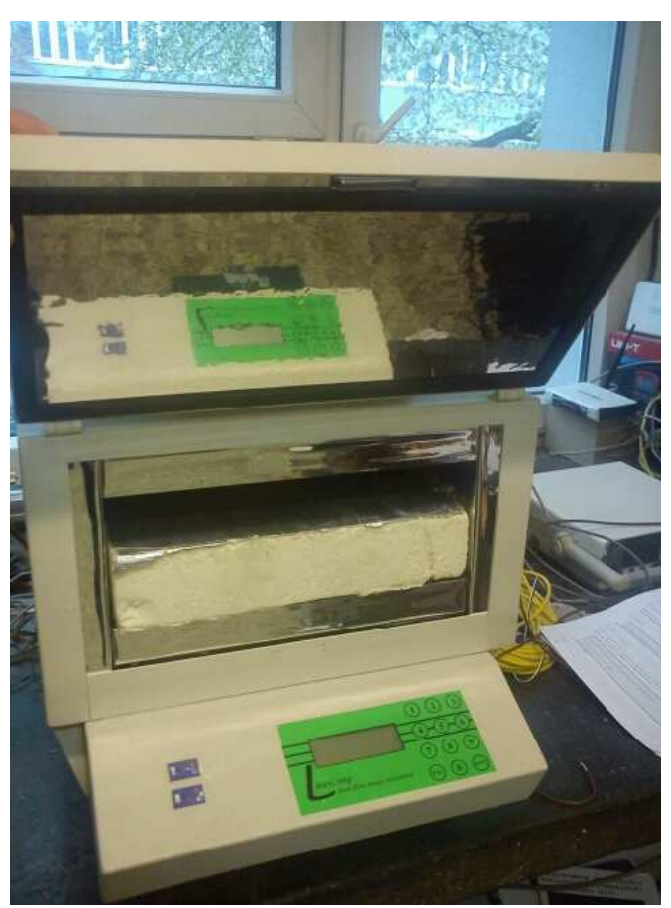

Rys. 1 Aparat płytowy FOX 314

Fig. 1. Heat Flow Meter FOX 314 parametrów cieplnych jako wartości średniej z pomiarów przeprowadzonych w okresie obejmującym pełne cykle zmienności warunków brzegowych. [5] Dużą wadą tej metody jest bardzo długi okres przeprowadzania pomiarów (od kilku do kilkunastu dni).

Pomiar metodą stacjonarną wykonany był $\mathrm{w}$ aparacie płytowym FOX 314 firmy LaserComp (rys. 1). Aparat dostarcza wiarygodnych i bardzo dokładnych wyników. Składa się z nieruchomej płyty górnej oraz z płyty dolnej, która ma możliwość ruchu w gorę i w dół, tak aby badana próbka dokładnie do niej przylegała. Na powierzchni każdej z płyt zamontowane są ciepłomierze $\mathrm{z}$ termoparami. Obie płyty wyposażono $\mathrm{w}$ zaawansowany system chłodząco-grzewczy. Zakres pomiarowy urządzenia wynosi $0,01-0,2 \mathrm{~W} / \mathrm{m} \cdot \mathrm{K}$.

\subsection{Metoda niestacjonarna pomiaru parametrów cieplnych i opis użytej aparatury}

Metody pomiarowe oparte na nieustalonym przewodzeniu ciepła umożliwiają szybkie wykonanie pomiaru. W większości przypadków sprowadzają się do wyznaczenia dyfuzyjności cieplnej w oparciu o pomiar zmiany temperatury w czasie nagrzewania lub chłodzenia próbki.

Pomiar może być realizowany w sposób dynamiczny przy użyciu przenośnego urządzenia ISOMET 2114 (Rys. 2). Ze względu na swoje małe gabaryty oraz krótki okres wykonywania pomiaru urządzenie może być używane w warunkach polowych.

Podstawę pomiaru stanowi analiza odpowiedzi termicznej na docierający do powierzchni próbki sygnał cieplny, przy założeniu że rozprzestrzenianie 
ciepła występuje w nieograniczonym ośrodku. Strumień ciepła generowany jest przez elektryczny rezystor - grzejnik, umiejscowiony wewnątrz sondy, która pozostaje $\mathrm{w}$ bezpośrednim kontakcie $\mathrm{z}$ testowaną próbką. Pomiar polega na rejestracji reakcji termicznej badanego materiału w funkcji czasu. Przyrząd jest wyposażony w dwa rodzaje sond pomiarowych (rys. 3): sondę igłową do pomiarów miękkich materiałów oraz sondę powierzchniową do materiałów twardych (ze względu na brak możliwości wywiercenia precyzyjnego otworu). Zakres pomiarowy sondy powierzchniowej deklarowany przez producenta to $0,04-0,30 \mathrm{~W} / \mathrm{m} \cdot \mathrm{K}$. Do pomiarów współczynnika przewodzenia w zakresie $0,015-0,05 \mathrm{~W} / \mathrm{m} \cdot \mathrm{K}$ dedykowana jest sonda igłowa. Ograniczeniem stosowania sondy igłowej są minimalne wymiary próbki wynoszące $80 \mathrm{~mm}$ x $40 \mathrm{~mm}$. Urządzenie ISOMET 2114 ma możliwość pomiarów różnorodnych parametrów cieplnych tj.: współczynnika przewodzenia ciepła , $\lambda$ ” $[\mathrm{W} /(\mathrm{m} \cdot \mathrm{K})]$, współczynnika dyfuzyjności cieplnej ,a” $\left[\mathrm{m}^{2} / \mathrm{s}\right]$, objętościowej pojemności cieplnej „, $\mathrm{C}_{\mathrm{q}}{ }$ $\left[\mathrm{J} / \mathrm{m}^{3} \cdot \mathrm{K}\right]$ oraz temperatury $\left[{ }^{\circ} \mathrm{C}\right]$.

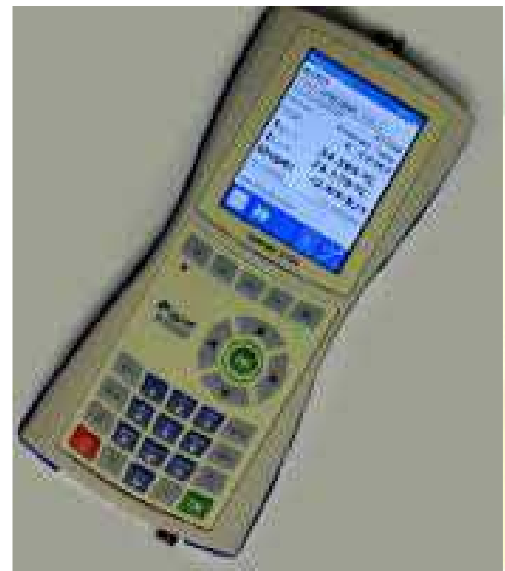

Rys. 2. Przenośne urządzenie do pomiaru parametrów termicznych ISOMET 2114

Fig. 2. Portable device for measuring the thermal performance ISOMET 2114

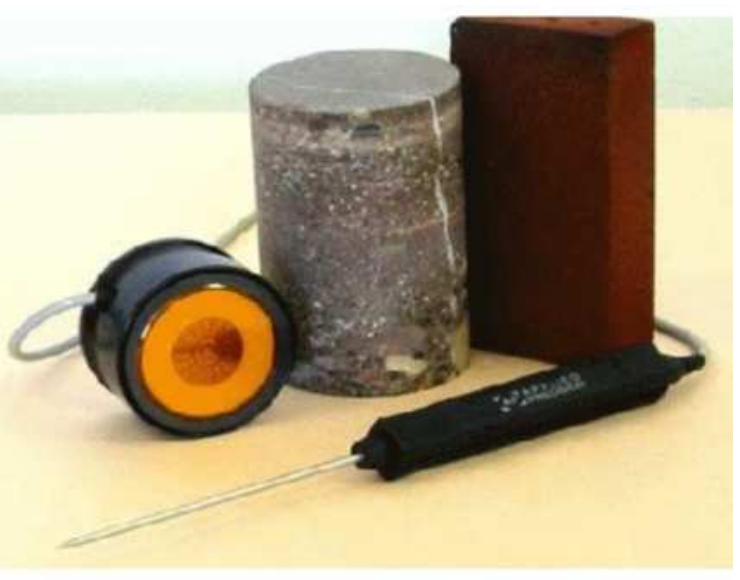

Rys. 3. Rodzaje sond pomiarowych kompatybilnych z urządzeniem ISOMET 2114

Fig. 3. Types of probes compatible with a measuring device ISOMET 2114

Pomiar współczynnika przewodzenia ciepła przeprowadzono dla 5 i 10 centymetrowych próbek następujących materiałów termoizolacyjnych: sztywna pianka poliuretanowa, styropian o gęstości $15 \mathrm{~kg} / \mathrm{m}^{3}$ i $16 \mathrm{~kg} / \mathrm{m}^{3}$, miękkie maty oraz twarde płyty $\mathrm{z}$ wełny mineralnej. Pomiar był przeprowadzony zarówno metodą stacjonarną (w urządzeniu FOX 314) oraz metodą niestacjonarną (przy użyciu przyrządu ISOMET 2114). Pomiary metodą stacjonarną były wykonywane przy temperaturze płyt 0 i $20^{\circ} \mathrm{C}$. Zarówno pomiar w aparacie płytowym jak i urządzeniem ISOMET przeprowadzone były w laboratorium, przy ustabi- 
Pomiar właściwości cieplnych materiałów budowlanych przy zastosowaniu różnej... 607

lizowanej temperaturze i wilgotności powietrza. Metoda dynamiczna obejmowała 20 serii pomiarowych, a prezentowane w tabeli 1 i 2 wyniki są wartościami średnimi. Uzyskane wyniki są zbieżne z zakresem wielkości współczynnika przewodzenia ciepła podawanego przez producentów materiałów termoizolacyjnych.

\section{Porównanie i analiza otrzymanych wyników}

Tabela 1 przedstawia porównanie wyników współczynnika $\lambda$ dla próbek styropianu o grubości $10 \mathrm{~cm}$. Do pomiarów metodą niestacjonarną użyto sondy igłowej. Średnia wartość współczynnika przewodzenia ciepła z pomiarów urządzeniem ISOMET różni się nie więcej niż 5\% w stosunku do wyników metody stacjonarnej. Wskazuje to na jej dużą dokładność.

Tabela 1. Wyniki pomiarów dla różnych rodzajów styropianu o grubości $10 \mathrm{~cm}$ Table 1. The results of measurements for different types of polystyrene having a thickness $10 \mathrm{~cm}$

\begin{tabular}{|c|c|c|c|}
\hline \multirow{2}{*}{ Aparatura } & \multicolumn{3}{|c|}{ Współczynnik przewodzenia ciepła } \\
\cline { 2 - 4 } & Próbka 1 & Próbka 2 & Próbka 3 \\
\hline $\begin{array}{c}\text { FOX } \\
\lambda_{\mathrm{F}}=\end{array}$ & 0,0404 & 0,03741 & 0,03141 \\
\hline $\begin{array}{c}\text { Isomet (sonda igłowa) } \\
\lambda_{\mathrm{I}}=\end{array}$ & 0,0417 & 0,035704 & 0,0319 \\
\hline Różnica $\left(\lambda_{\mathrm{F}}-\lambda_{\mathrm{I}}\right) / \lambda_{\mathrm{F}}, \%$ & $-3,22$ & 4,56 & $-1,56$ \\
\hline
\end{tabular}

Kolejnym etapem było wykonanie analogicznych pomiarów dla próbek o mniejszej grubości $(4-6 \mathrm{~cm})$. Ze względu na stosunkowo małą dokładność wyników metody dynamicznej przy użyciu sondy igłowej $(9,24 \%-39,43 \%)$ w kolejnej serii użyto sondę powierzchniową (Rys. 4, Tabela 2).

Różnice pomiędzy pomiarami wykonywanymi w aparacie FOX i Isomet z sondą powierzchniową wynoszą od $3,89 \%$ do $37,54 \%$. W przypadku przeprowadzonych przez autorów badań dla opisanej grupy materiałów wartości współczynnika przewodzenia ciepła pochodzące z urządzenia Isomet wykazują większe wartości niż otrzymane z metodą dokładną. Niezależnie od użytej sondy dokładność pomiarów metodą dynamiczną w przypadku małych grubości materiałów termoizolacyjnych jest niewystarczająca. 


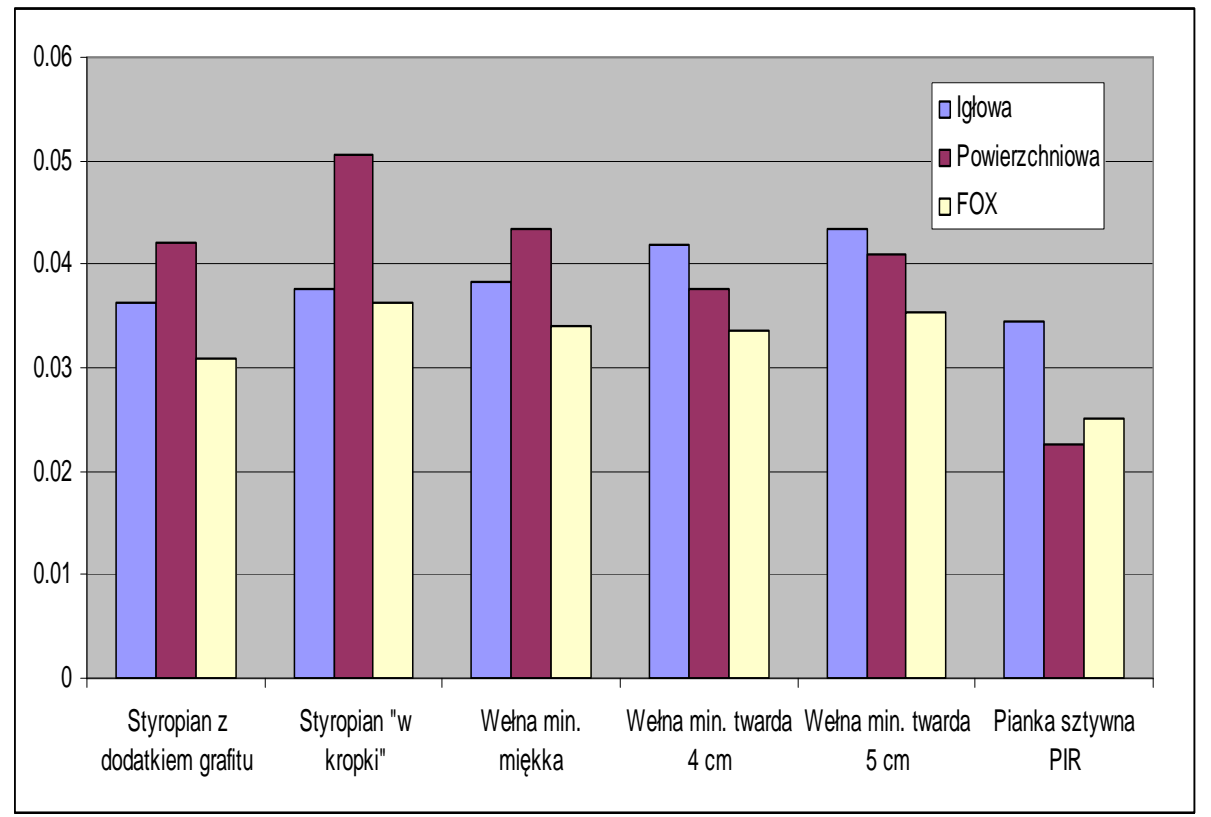

Rys. 4. Wyniki pomiarów dla różnych materiałów termoizolacyjnych o grubości 4-6 cm

Fig. 4. The results of measurements for different types of insulation materials having a thickness $4-6 \mathrm{~cm}$.

Tabela 2. Wyniki pomiarów dla różnych materiałów termoizolacyjnych i oszacowanie niedokładności pomiaru

Table 2. The measurement results for different types of insulation materials and an estimate of measurement error

\begin{tabular}{|c|c|c|c|c|c|}
\hline \multirow[b]{2}{*}{$\begin{array}{c}\text { Rodzaj } \\
\text { materiału }\end{array}$} & \multicolumn{2}{|c|}{$\begin{array}{l}\text { Współczynnik przewo- } \\
\text { dzenia, W/m·K Rodzaj } \\
\text { sondy }\end{array}$} & \multirow{2}{*}{$\begin{array}{c}\begin{array}{c}\text { Pomiar w } \\
\text { FOX }\end{array} \\
\square \square_{\mathrm{F}}\end{array}$} & \multicolumn{2}{|c|}{$\begin{array}{l}\text { Błąd w odniesieniu do } \\
\text { pomiarów w FOX }\end{array}$} \\
\hline & $\begin{array}{c}\text { Sonda } \\
\text { Powierzch- } \\
\text { niowa } \square \square \mathrm{P} \\
=\end{array}$ & $\begin{array}{l}\text { Sonda } \\
\text { Igłowa } \\
\square \square_{\mathrm{I}}=\end{array}$ & & $\begin{array}{c}\left(\square_{\mathrm{F}^{-}}\right. \\
\left.\square_{\mathrm{P}}\right) / \square_{\mathrm{F}}, \%\end{array}$ & $\begin{array}{c}\left(\square_{\mathrm{F}^{-}}\right. \\
\left.\square_{\square}\right) / \square_{\mathrm{F}}, \\
\%\end{array}$ \\
\hline Styropian 1 & 0,0362 & 0,042 & 0,03097 & $-16,89$ & $-35,62$ \\
\hline Styropian 2 & 0,0377 & 0,0506 & 0,03629 & $-3,89$ & $-39,43$ \\
\hline $\begin{array}{l}\text { Wełna min. mięk- } \\
\text { ka }\end{array}$ & 0,0383 & 0,0435 & 0,03398 & $-12,71$ & $-28,02$ \\
\hline $\begin{array}{l}\text { Wełna min. twar- } \\
\text { da } 4 \mathrm{~cm}\end{array}$ & 0,0418 & 0,0376 & 0,03356 & $-24,55$ & $-12,04$ \\
\hline $\begin{array}{l}\text { Wełna min. twar- } \\
\text { da } 5 \mathrm{~cm}\end{array}$ & 0,0435 & 0,0409 & 0.03533 & $-23,12$ & $-15,77$ \\
\hline $\begin{array}{l}\text { Pianka sztywna } \\
\text { PIR }\end{array}$ & 0,0344 & 0,0227 & 0,02501 & $-37,54$ & 9,24 \\
\hline
\end{tabular}


Pomiar właściwości cieplnych materiałów budowlanych przy zastosowaniu różnej... 609

\section{Podsumowanie i wnioski}

Współczesne tendencje skierowane są w kierunku ograniczania zużycia energii cieplnej w sektorze budowlanym, a co za tym idzie w kierunku minimalizacji strat ciepła i zaostrzania wymogów izolacyjności. Aktualne wymogi zmuszają inwestorów do stosowania bardzo grubych warstw termoizolacji. Tak więc niewielkie obniżenie współczynnika przewodzenia ciepła może skutkować redukcją wymaganej minimalnej grubości ocieplenia. Dlatego tez pomiar i znajomość tego parametru jest tak istotna.

Pomiar oparty na nieustalonym strumieniu ciepła (urządzeniem ISOMET 2114) jest możliwy w dowolnym miejscu, w zdecydowanie krótszym niż metody stacjonarne czasie. Niestety przeprowadzona analiza wykazała, że w przypadku materiałów termoizolacyjnych dokładność tej metody można uznać za wysoką jedynie w przypadku warstw o grubości $10 \mathrm{~cm}$. W przypadku cieńszych warstw materiału $(4-6 \mathrm{~cm})$ uzyskane wyniki mogą być obarczone znacznym błędem. Na podstawie przeprowadzonych badań dla wąskiego zakresu materiałów termoizolacyjnych zaobserwowano, iż wyniki uzyskane z pomiarów wykonanych przy użyciu przyrządu Isomet są w większości przypadków wynikami zawyżonymi (w porównaniu z wynikami otrzymanymi z pomiarów w aparacie płytowym jak i wartościami zawartymi w specyfikacji producenta).

\section{Literatura}

[1] E. Radziszewska - Zielina, Analiza porównawcza parametrów materiałów termoizolacyjnych mających zastosowanie jako termoizolacja ścian zewnętrznych, Przegląd budowlany 4/2009

[2] C. Oleśkowicz - Popiel, J. Wojtkowiak, Eksperymenty w wymianie ciepła, Wydawnictwo Politechniki Poznańskiej, Poznań 2004

[3] W. Miękina, S. Chudzik, Pomiary parametrów cieplnych materiałów termoizolacyjnych - przyrządy i metody, Wydawnictwo Politechniki Częstochowskiej, Częstochowa 2004.

[4] J. A. Pogorzelski, Fizyka cieplna budowli, Państwowe Wydawnictwo Naukowe, Warszawa 1976.

[5] T. Kisilewicz, A. Wróbel, Diagnostyka termowizyjna przegród w niestacjonarnych warunkach brzegowych. Fizyka budowli w teorii i praktyce, Czasopismo Naukowe tom IV, Politechnika Łódzka, Łódź 2009.

[6] Rozporządzenie Ministra Infrastruktury w sprawie warunków technicznych, jakim powinny odpowiadać budynki i ich usytuowanie z dnia 12 kwietnia 2002 r. (Dz.U. $\mathrm{Nr} 75$, poz. 690) ze późniejszymi zmianami.

[7] Instrukcja do urządzenia FOX 314

[8] Instrukcja do urządzenia ISOMET 2114

[9] G. Desogus, S. Mura, R. Ricciu, Comparing different approaches to in situ measurement of building components thermal resistance, Energy and Buildings 43 (2011) 2613-2620.

[10] V. Gori, C. A. Elwell, C. Scott, C. Rye, R. Lowe, T. Oreszczyn, Inferring the thermal resistance and effective thermal mass of a wall using frequent temperature and heat flux measurements Energy and Buildings 78 (2014) 10-16. 
[11] P. J. Bjørn, Traditional state-of-the-art and future thermal building insulation materials and solutions - Properties, requirements and possibilities, Energy and Buildings 43 (2011) 2549-2563.

[12] H. Garbaliństka, M. Bochenek, Izolacyjność termiczna a akumulacyjność cieplna materiałów ściennych, Czasopismo Techniczne 2011. Zeszyt $11: 89-96$.

[13] M. Sobolewski, K. Prekiel. Możliwości badawcze materiałów izolacyjnych w aparacie płytowym na przykładzie polistyrenu ekstradowanego. Czasopismo Techniczne Zeszyt 2012. 3: 388 - 394.

[14] L. Żabski, J. Papiński Pianki PIR - nowy typ izolacji typu sztywna pianka poliuretanowa, Izolacje 62012 (167.

[15] M. Rutowicz, Wykonanie izolacji cieplnych z pianki poliuretanowej, Materiały Budowlane 7/2012

[16] P. Cieślewicz, Nowoczesne termoizolacje przyszłości, Materiały Budowlane, $5 / 2012$

\title{
MEASUREMENT OF THERMAL PROPERTIES OF BUILDING MATERIALS THROUGH THE USE OF DIFFERENT MEASURING EQUIPMENT - ANALYSIS OF RESULTS
}

\begin{abstract}
S u m m a r y
The aim of the article is to verify the thermal parameters of building materials obtained by using two different methods. Methods for measuring thermal performance of building materials can be divided into two main groups: stationary methods (implemented with a fixed heat flux) and the non-stationary methods (implemented with the transient heat flux). The article contains an analysis of opportunities for relatively rapid tests using a mobile device, which operation is based on a dynamic method. The results are compared to the values obtained from measurements in a very accurate and recommended instrument for measuring thermal conductivity. Measurements were carried out on samples commonly used insulation materials such as $\therefore$ rigid polyurethane foam, polystyrene and mineral wool (mat soft and hard boards) having thicknesses of $4-6 \mathrm{~cm}$ and $10 \mathrm{~cm}$. Article also examines the possibility of using different types of sensors that work with the mobile device. The big advantage of the mobile device is that it can be used in field tests. Unfortunately, the analysis showed that in case of thermal insulation materials accuracy of this method can be considered high only for layers with a thickness of $10 \mathrm{~cm}$. In case of lesser thickness of insulation $(5 \mathrm{~cm})$ obtained measurement results may be subjected to considerable error. Based on the survey for a narrow range of thermal insulation materials it was observed that the results obtained from measurements made using the instrument Isomet are in most cases overestimated, compared to both the research on the heat flow meter and these contained in the manufacturer's specifications.
\end{abstract}

Keywords: thermal conductivity, conductivity, testing thermal parameters

Przestano do redakcji: $28.11 .2014 \mathrm{r}$.

Przyjęto do druku: 22.06.2015 r.

DOI:10.7862/rb.2015.89 